\title{
SISTEMAS DE INFORMAÇÃO GEOGRÁFICA: UMA ARMA ESTRATÉGICA PARA O DATABASE MARKETING
}

\author{
Francisco Aranha \\ E-mail faranha@eaesp.fgvsp.br \\ Professor do Departamento de Informática e \\ Métodos Quantitativos da EAESP/FGV e \\ Consultor de Empresas.
}

RESUMO: Os Sistemas de Informações Geográficas (SIG) tornaram-se disponiveis para uso em computadores de mesa, sendo extremamente adaptáveis para as atividades de marketing de relacionamento. Uma caracteristica desses sistemas é que permitem uma análise de dados de forma praticamente inviável com outras ferramentas. A sua utilização depende da existência de mapas e dados possivelmente caros e dificeis de obter. No Brasil, seu uso vai popularizar-se nos próximos dois anos.

ABSTRACT: Geographic Information Systems (GIS) have become available for desktop computers; they are extremely useful for Database Marketing activities and allow data analysis virtually unfeasible with other tools. Their application, however, depends on the existence of maps and data potentially expensive and difficult to obtain. Geographic Information Systems usage will become popular in Brazil in the next two years.

PALAVRAS-CHAVE: marketing de relacionamento, sistemas de informaçōes geográficas, mapeamento, geografia de mercado.

KEYWORDS: database marketing, geographic information systems, mapping, market geography. 
O aumento da capacidade de armazenamento e processamento de dados dos computadores de hoje, e seus preços cada vez mais acessíveis, estão provocando uma revolução na forma como as empresas conduzem atividades de marketing. As evidências vêm de informações variadas:

- mais da metade dos anúncios americanos pedem algum tipo de resposta direta;

- no Reino Unido, os gastos com marketing direto estão crescendo a uma taxa real superior a $30 \%$ ao ano, ou seja, muito mais rápido do que os gastos com TV;

- o uso do telemarketing vem dobrando anualmente, o que transformou o telefone no maior meio de comunicação isolado nos Estados Unidos;

- a lista de empresas que recentemente passaram a empregar as técnicas de marketing de relacionamento inclui organizações de todos os setores da economia, de todos os portes ${ }^{1}$.

Esta é uma revolução silenciosa porque está se dando sem alarde. Evoluiu suavemente a partir das tradicionais técnicas de marketing direto, sem ruptura com as práticas anteriores. No entanto, houve, indubitavelmente, um salto qualitativo que justifica a avaliação de vários autores ${ }^{2}$, de que estamos diante de um novo paradigma de marketing. Uma única editora de São Paulo, líder de mercado na área de temas empresariais, publicou, nos últimos dois anos, dez títulos sobre este assunto, atingindo uma tiragem global de 20.000 exemplares $^{3}$. Revolução silenciosa, sim. Invisível, não. A julgar pela venda de livros especializados, há milhares de profissionais atentos ao que se escreve sobre database marketing.

\section{DIÁLOGO EM VEZ DE MONÓLOGO}

O novo marketing é orientado por informações detalhadas sobre clientes e mercados, seu comportamento e suas reações às ações da empresa. Tem por objetivo a criação e a sustentação de um fluxo de "comunicação de mão dupla", gerenciado pela tecnologia de bancos de dados.

A idéia básica envolve uma mudança de conduta: em vez de se lançarem sobre o público alvo, num monólogo surdo, filmes, catálogos, páginas de revista e outdoors a respeito de determinado produto, procura-se estabelecer um diálogo. A escuta atenta de cada cliente individual permite descobrir, por exemplo, quando ele pretende comprar o produto, quando vai precisar de atendimento, em que ou-

Inicialmente
desenvolvidos, na
década de 60, para
companhias
mineradoras e
petrolíferas, e para
departamentos
governamentais de
planejamento da
ocupação do solo, os
GIS foram recentemente
descobertos pelas
empresas industriais e
comerciais em geral.

tros produtos estaria interessado etc. Em seguida, essas informações são lançadas no computador, para que o sistema permita à empresa retornar ao cliente de maneira precisa, no momento adequado, e com o produto que ele deseja.

As ações de marketing devem, necessariamente, ser desenhadas para produzir $e$ capturar as informações relevantes. Estas, por sua vez, devem, necessariamente, ser transformadas em lucro. É preciso evitar, a todo custo, a tentação de acumular dados inúteis, ainda que interessantes, e também o desperdício de oportunidades pelo abandono de informações preciosas, deixadas adormecidas nos arquivos da empresa.

\section{Segmentação}

$\mathrm{Na}$ base do sucesso em marketing de relacionamento, está a identificação detalhada de um grande número de segmentos específicos e homogêneos de clientes, correntes ou prospectivos, sobre os quais
1. SHAW Robert, Stone, Merlin. Database marketing. USA: Gower, Hants, 1988, p.7.

2. Veja, por exemplo: SHEPARD, David et al. Database marketing: o novo marketing direto. São Paulo: Makron Books, 1993; KOBS, Jim. From MD to DM. Săo Paulo: Makron Books, 1993; SOUZA, Francisco Alberto Madia de. Introdução ao marketing de sexta geração. Săo Paulo: Makron Books, 1994.

3. Informação fornecida pela Editora Makron Books. 
atuar. Para isso, é necessária muita informação. A atenção às particularidades de cada grupo estreitamente definido é que permite oferecer os meios exatos para a satisfação precisa de suas necessidades. Isto é mais fácil falar do que fazer. Uma segmentação competente resulta de um processo longo e complexo. É preciso confirmar que os segmentos existem, determinar as características e a localização de cada um e descobrir como alocar cada cliente ou prospect no segmento correto ${ }^{4}$.

Para lidar com essas tarefas, nos estágios que envolvem aspectos de localização, qualquer empresa pode hoje contar com auxílio dos GIS (Geographic Information Systems), que são, afinal, o objeto deste artigo. Este trabalho busca chamar atenção para as possibilidades abertas pelo GIS para os profissionais de database marketing.

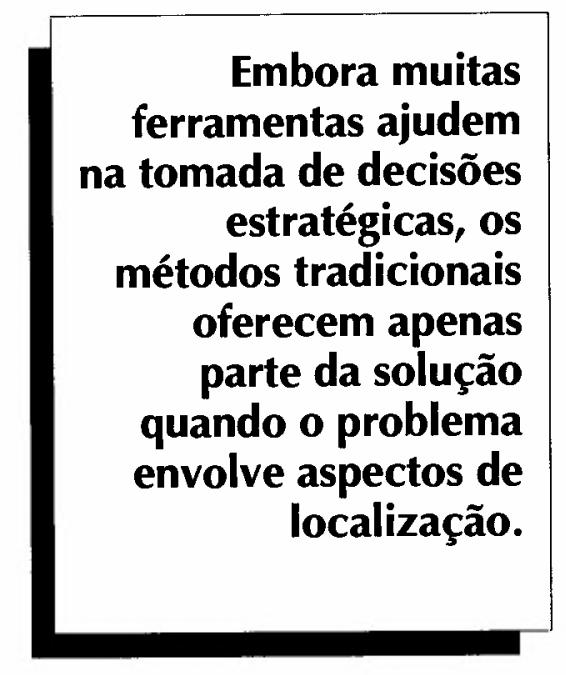

\section{SISTEMAS DE INFORMAÇÕES GEOGRÁFICAS}

4. SHEPARD, David. Op. cit., p. 25.

5. PAREDES, Evaristo. Sistemas de Informaçáa Geográfica - SIG. São Paulo: Érica, 1994.

6. GIS - Geographic Information Systems: vital to business presentations. Presentation Development \& Delivery, v. 15, n..2, Apr. 1992

7. ARAGON, Lawrence. Valley firm's software maps crime patterns. Business Journal, San José, California, week of November 2, 1992. passando, nos Estados Unidos, de US\$ 31 milhões, em 1991, para estimados US\$ 211 milhões em $1995^{6}$.

As empresas produtoras de software de mapeamento entraram em crescimento acelerado. Entre 1990 e 1992, a Strategic Mapping Inc., uma das duas líderes de mercado, triplicou a área que ocupava, estendendo-a para cerca de $3.000 \mathrm{~m}^{2}$. No mesmo período, quadruplicou o seu número de funcionários, atingindo um quadro de 110 colaboradores ${ }^{7}$. Representante no Brasil de sua arqui-rival, a MapInfo Corp., informa que o faturamento líquido dessa empresa passou de US\$10,58 milhões, em 1992, para US $\$ 29,72$ milhões em 1994, e que o seu quadro de funcionários, que contava com 89 pessoas em 1993, passou para 285, em 1995. Estes números são significativos, uma vez que empresas de software costumam ser pequenas, terceirizando uma parte significativa dos seus desenvolvimentos.

\section{Crescimento justificável}

A elevada taxa de expansão dessas empresas é bastante compreensível. Embora muitas ferramentas ajudem na tomada de decisões estratégicas, os métodos tradicionais oferecem apenas parte da solução quando o problema envolve aspectos de localização. Um software de mapeamento permite associar informações de um banco de dados a um mapa e, por meio dele, identificar padrões, entender tendências, quantificar variáveis, analisar mercados e alocar recursos. A ferramenta é poderosa. Não se trata apenas de produzir belas imagens. Os GIS permitem "espremer" os dados eficientemente, produzindo compreensões que não estariam disponíveis de outra forma, já que relações espaciais dificilmente podem ser representadas, em gráficos ou tabelas, de maneira adequada.

\section{Um casamento feliz}

Embora a gama de aplicações dos GIS a questões empresariais seja bastante ampla, a estrutura dos programas líderes de mercado os faz particularmente bem adaptados para o database marketing. Os GIS gerenciam e integram três tipos de arquivos: bancos de dados, arquivos geográficos e arquivos de pontos.

Os arquivos geográficos contêm as "en- 
tidades geográficas" (áreas, linhas e pontos) definidas por suas coordenadas (latitude e longitude), e servem para produzir os mapas propriamente ditos. Formam a parte mais crítica, e cara, do sistema. Os mapas que costumam acompanhar "gratuitamente" o software são muito genéricos, e qualquer análise útil certamente envolverá a necessidade de aquisição de cartas adicionais. Estas nem sempre estão disponíveis para uma ou outra marca de aplicativo, e freqüentemente devem ser digitalizadas especialmente para o cliente.

De maneira geral, os arquivos de dados podem estar em qualquer um dos formatos mais populares, como dBASE, Excel, Lotus 123, ASCII e SQL. A maneira como os tipos de arquivo são tratados varia de aplicativo para aplicativo. Ou eles são abertos diretamente pelo programa, ou são importados, ou é estabelecida uma conexão externa com o banco de dados. Seja como for, os dados podem ser associados aos entes geográficos por uma chave comum. Informações típicas dos arquivos de dados seriam aquelas puramente externas à empresa, como as relativas a dados econômicos, demográficos e psicossociais do mercado.

O terceiro tipo de arquivo é um híbrido dos primeiros dois. Os arquivos de pontos incluem informações associadas a localizações pontuais que não constituem entidades geográficas duradouras. $O$ caso clássico seria um banco de dados sobre clientes. Estes, uma vez devidamente geocodificados a partir do seu endereço, código de endereçamento postal ou outro atributo, podem ser "colocados no mapa". Além disso, os dados disponíveis a seu respeito ficam associados à sua localização e podem ser manipulados levando esta informação em consideração.

A interação destes três grandes blocos permite a montagem dos mapas, a aplicação de cores, padrões e símbolos (para representar simultaneamente diversos tipos de dados) e a realização de diversos cálculos de agregação, desagregação e estatísticos.

O produto final típico pode ser uma análise de potencial de mercado, de segmentação, de localização de bases de clientes e prospects, ou de localização de filial. Pode ser também o planejamento e a

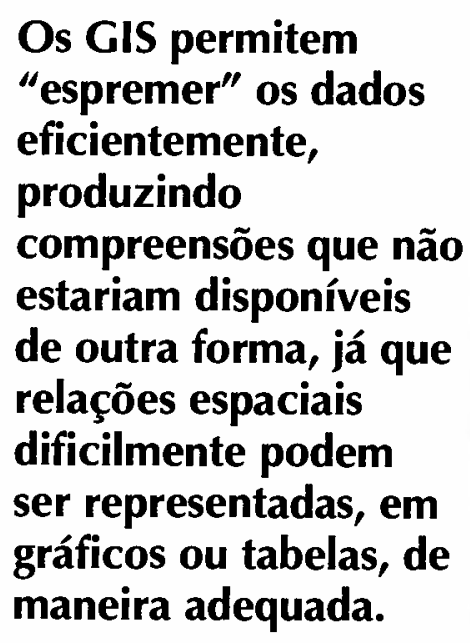

projeção de respostas a campanhas ou a projeção de tendências de mercado, enfim qualquer um dos inúmeros estudos em que a localização é importante.

Se o enfoque é quantitativo, pode-se obter respostas para perguntas como: Quantos e quais clientes estão a menos de $50 \mathrm{~km}$. do nosso depósito? Quanto vendemos do nosso produto em determinada região? Qual é o potencial de venda dos produtos nesta região? Qual é a população na área de influência de determinado ponto comercial? Qual é a renda disponível dentro de determinado bloco de CEPs? E muitas outras.

\section{Um pouco de realismo}

Os benefícios do emprego dos GIS são grandes e variados, mas requerem um esforço que não é trivial. Há problemas a serem enfrentados.

Ocusto de entrada para um sistema com configuração completa varia, hoje, entre $R$ \$ 3.000 e R $\$ 5.000$. Um mapa detalhado, com eixos e numeração de rua, para uma cidade como São Paulo, custa cerca de $R \$ 3.200$ adicionais. Mas esses preços tendem a diminuir à medida que entrarem outros fornecedores no mercado e à medida que houver aumento da base de usuários, permitindo ratear os custos de criação das bases de dados entre uma quantidade maior de clientes. Isso deverá acontecer logo, embora o preço não seja o mais importante fator restritivo ao uso dos programas.

A principal dificuldade está na pequena disponibilidade de mapas e bancos de 
8. Para se ter uma idéia da dimensāo deste cuidado, 0 autor óste artigo levou, na fase de familiarizacẫo com o programa, dez dias úteis, de dedicação quase exclusiva. Ao final ainda nāo conseguia usá-ío direito, mas estava preparado para enfrentar o treinamento, munido de uma extensa lista de dúvidas.

9. A propósito da planilha eletrônica, parece que o Microsoft Office para Windows 95 inclui dentro do Excel, um pequeno módulo de mapeamento produzido pela Maplnfo. dados. Eles até existem, dispersos entre vários órgãos públicos e empresas privadas, mas nem sempre estāo à venda e quase certamente estão em formatos incompatíveis (entre si e com o programa), exigindo muito trabalho para serem colocados em forma útil.

Antes de se adquirir algum dos programas existentes no mercado, deve-se certificar dos mapas e bancos que integram o pacote e do preço dos demais itens necessários e que serão comprados em separado. Deve-se negociar no momento da aquisição: há possibilidade de se conseguir a inclusão de bases adicionais, sem custo ou por um preço promocional. Um outro cuidado refere-se ao detalhado exame da documentaçāo que acompanha os bancos de dados: como os fornecedores nacionais não estão muito preocupados com os "detalhes", há o risco de se comprar um disquete contendo uma tabela-monstro, cheia de campos cuja origem, significado e data de atualização sejam impossíveis de se descobrir.

Isto não é tudo. Os dados internos da maioria das empresas, convenhamos, são assistemáticos, estão espalhados pelos diversos departamentos e foram desenhados para operaçōes relacionadas às vendas passadas (contabilidade, expedição, faturamento, cobrança etc.), não para gerar vendas futuras. Antes de colocar o GIS em funcionamento, o homem demarketing terá muito trabalho a realizar dentro de casa, $\mathrm{e}$ o primeiro passo será, provavelmente, conseguir a atenção do sempre sobrecarregado gerente da área de informática.

Finalmente, deve-se ter em mente que, como consequiência da própria extensăo $e$ riqueza do assunto tratado pelos GIS, os programas são complexos. Aprender a utilizá-los vai exigir dedicaçāo e comprometimento. Um treinamento de alguns dias com o fornecedor é indispensável, e deve preferencialmente acontecer depois do usuário ter lido os manuais, feito os tutorials e tentado empregar o GIS sobre algum problema da empresa ${ }^{8}$.

\section{CONCLUSĀO}

Se, no seu trabalho, você analisa informações ligadas a algum tipo de localização, expor-se a um GIS é apenas uma questão de tempo. Estes sistemas deverão se tornar um tipo de planilha eletrônica: se hoje é difícil imaginar um dia de trabalho sem planilhas, o que se dirá de uma versāo eletrônica destas?.

Finalmente, se você atua em marketing, particularmente marketing de relacionamento, e ainda nāo examinou os Sistemas de Informações Geográficas, tudo indica que você está perdendo tempo. Trate de correr.

\section{O MAPA DA MINA}

Para detalhes mais técnicos a respeito do funcionamento dos programas de mapeamento, e para uma visāo panorâmica dos principais fornecedores de software, suas vantagens $\mathrm{e}$ desvantagens, recomendo a leitura de artigos de Robert Kendal $e$ de Ben Smith e Howard Eglowsteln*.

Estes dois artigos fornecem um bom panorama do que está disponivel. Desde sua publicaçâo, um sem número de novas versōes foram lançadas pelas companhias de software, mas os programas mais importantes continuam os mesmos.

As novidades têm sido comentadas passo. a passo pelas revistas especializadas em informática, mas nâo sei se vale a pena refazer todo 0 percurso da corrida pela preferência do consumidor. 0 interessante nesta disputa é apenas o fato de que os principais competidores têm se alternado na liderança, com pequena vantagem, a cada novo lançamento. Desta briga resultou um impressionante aperfeiçoamento dos programas e uma notável reduçăo nos preços. 0 benefício é nosso.

Quando chegar o momento de fazer a sua escolha, procure informar-se sobre as últimas versōes de cada um - e sobre as próximas - para evitar comprar uma versão às vésperas do lançamento da seguinte. Certifique-se de ter considerado 0 Mapinfo (versão em português aguardada para março de 1996), o Atlas Gis (versão em português aguardada para o segundo trimestre de 1996), e o Tactician (especifico para aplicaçōes mercadológicas). E lembre-se: investigue bem a existência e 0 preço dos mapas e dados de que você precisa.

* KENDAL, Robert Mapping software: analyzing a world of data. PC Magazine, New York, p. 249-75, July 1991; SMITH, Ben, EGLOWSTEIN, Howard. A dinâmica da geografia digital: programas de mapeamento. Byte, São Paulo, n.4, p. 97-107, abr. 1993 